anbiances Environnement sensible, architecture et espace urbain Varia | 2020

\title{
Immersivity: An Interdisciplinary Approach to Spaces of Immersion
}

Immersivité: Une approche interdisciplinaire aux espaces d'immersion

Florian Freitag, Céline Molter, Laura Katharina Mücke, Helena Rapp, Damien B. Schlarb, Elisabeth Sommerlad, Clemens Spahr and Dominic Zerhoch

\section{OpenEdition}

\section{Journals}

Electronic version

URL: http://journals.openedition.org/ambiances/3233

DOI: 10.4000/ambiances.3233

ISSN: 2266-839X

\section{Publisher:}

Direction Générale des Patrimoines - DAPA - MCC, UMR 1563 - Ambiances Architectures Urbanités (AAU)

\section{Electronic reference}

Florian Freitag, Céline Molter, Laura Katharina Mücke, Helena Rapp, Damien B. Schlarb, Elisabeth Sommerlad, Clemens Spahr and Dominic Zerhoch, « Immersivity: An Interdisciplinary Approach to Spaces of Immersion », Ambiances [Online], Varia, Online since 11 December 2020, connection on 15 December 2020. URL : http://journals.openedition.org/ambiances/3233 ; DOI : https://doi.org/ 10.4000/ambiances.3233

This text was automatically generated on 15 December 2020.

\section{cc)}

Ambiances is licensed under a Creative Commons Attribution-NonCommercial-NoDerivatives 4.0 International License. 


\title{
Immersivity: An Interdisciplinary Approach to Spaces of Immersion
}

\author{
Immersivité: Une approche interdisciplinaire aux espaces d'immersion \\ Florian Freitag, Céline Molter, Laura Katharina Mücke, Helena Rapp, \\ Damien B. Schlarb, Elisabeth Sommerlad, Clemens Spahr and Dominic \\ Zerhoch
}

\section{Introduction ${ }^{1}$}

1 On a drizzly December morning, we - two scholars in American Studies, two human geographers, one film scholar, one anthropologist, and one scholar in theatre studies are standing in the middle of the maritime "Harbor Christmas Market" on the banks of the Rhine in Cologne. Between sparsely frequented Christmas booths with nautical decorations, we discuss our impressions of the venue's atmosphere and overall immersive potential. Christmas markets are more or less gated themed spaces. For central Europeans, these markets are familiar enough as a setting, yet unfamiliar enough to experience them as a break from the ordinary. However, virtually all of us noticed that the market's various atmospheres jarred with the holiday cheer that the market setting ostensibly tried to evoke. Having brought distinct disciplinary approaches and tools to the situation, we walked away realizing that they were not too helpful to analytically tackle our experience. Immersion remained as elusive as atmospheres.

2 However, by drawing on their shared spatial qualities, we may use the former experience to get closer to the latter. Spatiality is one of the ways in which atmospheres shape our perception. Hence, understanding atmospheres requires that we first understand their spatial qualities. Attending to designed spaces such as Christmas markets, we argue, can help us in this endeavor: on the one hand, spatiality is an inherent feature of human perception. In this sense, we are bound by spaces. On the other hand, designed or produced spaces have the distinct advantage of allowing us to impose and trace tangible limits on our atmospheric perception, thus potentially 
opening up at least one aspect of atmospheres to analysis. Understanding atmospheres by way of spaces thus necessitates, among other things, that we comprehend the immersive potential of designed spaces. This is what we want to call immersivity, and it is in this sense that immersivity can help us understand atmospheres.

In fact, what our various disciplinary approaches did allow us to do was discuss those aspects of the market that theoretically should have produced immersion. When we reflect on our individual responses, the question whether spatial and medial tools and strategies for producing immersion - or what we will here call immersivity - can be defined across disciplines moves into focus. Discussing these issues particularly becomes viable in an interdisciplinary discourse that takes seriously the purchase afforded by existing disciplinary traditions and challenges the limitations of those traditions in a collaborative exchange.

4 The term "immersion" figures in multiple academic discourses yet remains conceptually, terminologically, and methodologically fuzzy. Depending on the context, immersion may designate either a specific state of mind or a set of properties, found in either objects or practices, that contributes to generating such a state of mind. Researchers have thus developed subject- and object-oriented approaches to immersion. Adding to this conceptual confusion is a linguistic one. Immersion may take on any number of metaphorical permutations, for instance by designating feelings of submersion (in water), sensory overload, as well as the notion of being involved (sometimes: being lost) in an activity or story. Some definitions of the term even encompass both the prerequisites as well as the effects of immersion. Even when we reduce the debate to the two mainline arguments (immersion as subjective phenomenon vs. immersion as objective property), we are still left with the problem of articulating the relationship between these two standpoints. As with many theoretical terms, the linguistic gestures around the term immersion matter because they shape the methodology necessary for studying the phenomenon. What we would like to suggest in this article is, on the one hand, a clear differentiation between the two approaches to the phenomenon, and, on the other hand, a precise terminological instrumentarium that reflects this differentiation.

5 More precisely, we argue that immersivity is (1) a distinct term that denotes (2) an inherent quality of objects in general and of mediated, and thus delineated, real and imagined spaces in particular. (3) Building on Wolf's intersectional model (see fig. 1), we assume that those spatial qualities and modes interact in particular ways to generate immersion. These constellations are dynamic and context-sensitive, i.e. they depend on the spaces in question and their attendant topological imaginaries. Elucidating these interactions requires discussing examples from different disciplinary contexts. (4) And it is precisely through this interdisciplinary approach that we take a first step towards understanding immersivity. We do not seek to present a unified theory and methodology of immersivity but rather to pinpoint cross-disciplinary congruences wherever possible. The following considerations may nevertheless lead, in the long run, to a transdisciplinary, qualitative, experimental, and analytical model. Following a theoretical introduction to the topic of immersion, we will first conceptualize our interdisciplinary understanding of immersion and immersivity and then launch into a transdisciplinary dialogue about examples of immersive spaces from theme parks and film to theatre and educational spaces. 


\section{Conceptualizing Immersion and Immersivity}

6 Derived from Latin immergo (to plunge, dip, or sink into liquid), the English term "immersion" is still used literally, e.g. in the context of sacral rites and liturgy for the administration of Christian baptism. In what has become one of the most frequently cited statements on immersion, Janet Murray, in Hamlet on the Holodeck (1997), draws on this literal meaning, when she notes that we "seek the same feeling from a psychologically immersive experience that we do from a plunge in the ocean or swimming pool: the sensation of being surrounded by a completely other reality, as different as water is from air, that takes over all of our attention, our whole perceptual apparatus" (Murray, 1997, p. 98-99).

7 Murray employs the adjective "immersive" metaphorically to argue that what those who engage in such experiences desire are affective shifts in their consciousness. Many have followed in her footsteps, using "immersion" interchangeably with such concepts as "engagement" (Bentham, 1871), "presence" (Minsky, 1980), "flow" (Csíkszentmihályi, 1990), "involvement" (Calleja, 2007; Neitzel, 2008), "incorporation" (Calleja, 2011), "absorption" (Wolf, 2012), or "aesthetic illusion" (Wolf, 2013). For instance, in Virtual Art: From Illusion to Immersion, Oliver Grau, referring to the visual arts, speaks of "a high-grade feeling of immersion, of presence" (Grau, 2003, p. 7). Werner Wolf, in "Aesthetic Illusion", likewise defines immersion as "an experiential, predominantly emotional diving into a represented world" (Wolf, 2013, p. 23) and identifies aesthetic illusion as "predominantly a state of imaginary immersion" (p. 16).

Marie-Laure Ryan reiterates the slipperiness of immersion as a conceptual footing in Narrative as Virtual Reality 2, pointing out that the term has been discussed "from both a technological and a phenomenological point of view" (Ryan, 2015, p. 9). In particular the adjective "immersive" has been used in both subject-centered, reception-oriented, or - in Ryan's terms - phenomenological approaches as well as in object-centered, production-oriented, or technological studies, where it denotes the potential of a particular setup to induce an experience of immersion. Ryan sees Grau's "high-grade feeling of immersion, of presence" as the result of "immersive image spaces," engendered by media such as the fresco room, the panorama, or the circular cinema that address the eye "with a totality of images" (ibid., p. 5; our emphasis). In the same context, video game designers Katie Salen and Eric \& Heather Zimmerman caution against what they called "immersive fallacy," the notion that games isolate players from the natural and social world to achieve immersion (Salen/Zimmerman, 2003, p. 450 and f.). Wolf speaks in a similar constructivist vein of "immersive architecture" (Wolf, 2013, p. 15; our emphasis), while Ryan insinuates that it is really the acceleration of images that allows media to engender immersion, for in "contemporary culture, moving pictures are the most immersive of all media" (Ryan, 2015, p. 85; our emphasis). While Grau, Wolf, and Ryan differentiate between the two conceptual approaches to immersion, they all agree that immersive objects, media, and art forms engender experiences or feelings.

9 Other scholars have also tried to distinguish terminologically between a subjectcentered, reception-oriented, phenomenological approach and an object-centered, production-oriented, technological one. In Understanding Virtual Reality, for instance, William Sherman and Alain Craig suggest using "mental immersion" for the "state of being deeply engaged; suspension of disbelief; involvement" and "physical immersion" 
for the "property of a VR system that replaces or augments the stimuli to the participant's senses" (Craig, Sherman, 2018, p. 10). In "Film in Depth" film scholar Adriano D'Aloia speaks of a "sense of immersion" or "experiences of immersion" (D'Aloia, 2012, p. 95) and differentiates those from "immersivity," the "technical means and special effects" necessary for conveying "the impression of really being in the space of the fictional events depicted and an intense sensorial experience" (p. 89). Immersivity here suggests a special quality that dwells within the means of engendering immersion. D'Aloia seems to agree with Maurizio Forte, who similarly identifies "immersivity" as a gradable property of VR systems, noting that the "level of immersivity determines the sense of embodiment and sense of 'presence' in the environment" (Forte, 2012, p. 70).

D'Aloia and Forte were not the first to use the term "immersivity," but they used it to distinguish the state of mind from the set of properties of an object. Meanwhile, most scholars have employed "immersivity" synonymously with "immersion," grammatical sensibilities notwithstanding. Galimberti et al., for instance, speak of "phase(s) of immersion" and "phase(s) of non-immersivity" (Galimberti et al., 2001, p. 143); and Ronchi defines "immersivity" as "the level of sensory and emotional involvement that captures the user and links them to the application" (Ronchi, 2009, p. 160). Confusingly, both immersion and immersivity appear in the literature as referring to both a form of reception - a state of mind - and a quality found in objects or activities.

This is where we would like to intervene. To escape the conceptual and terminological quagmires that surround immersion, we propose following D'Aloia and Forte and differentiating between immersion as a state of mind and immersivity as an object's ability of fostering immersion. Immersivity, then, designates a process of production, whereas immersion is a process of reception. Differentiating these terms allows us to pivot the analysis to the production side. i.e. towards the inherent properties of clearly delineated objects rather than speculating about mental states or even about the relation between immersion and immersivity.

For if we posit that "immersion" and what we now call "immersivity" are distinct phenomena, their relationship becomes key. Are they mutually constitutive or two ends of a causal chain? There is reason for doubt on whether immersivity and immersion are bound in as direct a correlation, for instance, Forte and others would have it. Grau is one of very few scholars who subscribe to a mechanical, deterministic conception of the relationship between immersivity and immersion, where the presence of certain medial features - in Grau's case, “360 images" (Grau, 2003, p. 5) automatically "produc[es] the most intensive feelings of immersion possible" (p. 15). This lines up with behavioral social psychology approaches which address immersion by discussing the concept of priming. ${ }^{2}$ Wolf, by contrast, allows various other factors to play a role as well, arguing that "like all reception effects," aesthetic illusion (or immersion) is "elicited by the conjunction of factors that are located (a) in the representations themselves, which tend to show certain characteristic features and follow certain illusion-generating principles, (b) in the reception process and the recipients, as well as (c) in framing contexts, e.g. cultural-historical, situational, or generic ones" (Wolf, 2013, p. 52).

13 In fact, most scholars have conceived what we here call immersivity as merely one in an entire array of factors that, taken together, induce immersion or an immersed state of mind. This array also includes "the willingness to ignore [those elements] that might 
destroy the illusion of another reality" (Lonsway, 2009, p. 125; lyrical poet Samuel Coleridge's famous "willing suspension of disbelief for the moment" (Coleridge, 1817, p. 52)). Scholars such as Saler (2012) even argue that this process of actively ignoring the limits of illusion needs to be consciously reflected upon in the subject's mind for immersion to occur.

Figure 1: Wolf's Factors of Aesthetic Illusion

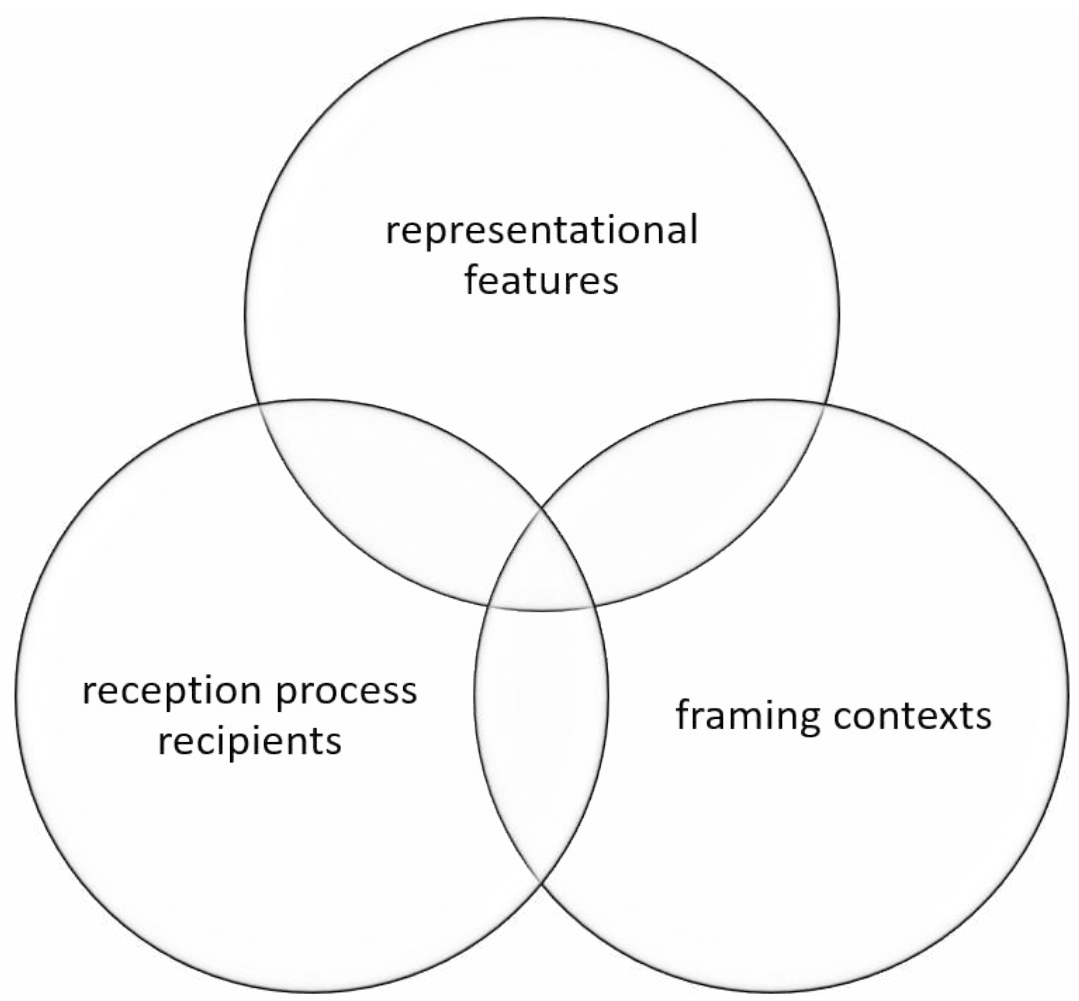

(Source: Wolf, 2013, p. 52, copyright: the authors)

These entanglements and caveats have profound implications for the methodology necessary to study immersivity (and immersion): we cannot simply measure immersion by 'counting the number of the users' senses that are provided with input and the degree to which inputs from the physical environment are 'shut out" (Lombard/ Ditton, 1997), as Matthew Lombard and Theresa Ditton have suggested. However, by the same token, counting the number of senses addressed and the extent to which input from the physical environment is "shut out" is precisely what the "measuring" of immersivity would entail. Such measurements appear more feasible, when they are conducted on the production side of the immersive equation and tied to the specific spatial configurations that are supposed to immerse a subject.

Hence, we use immersivity as a means for comprehending immersive spaces. Doing so allows us to focus on the much more readily available data and properties found in objects and processes that may (or may not) inspire immersion, properties, such as their multi-sensoriality or their strategies of keeping the "real world" at bay. Immersive spaces like theme parks, theatre, films, video games, or learning environments constitute materially and socially constructed territories that are offset from the everyday world by a threshold and governed by a limited number of rigorous and easily discernible rules concerning their sensoriality. It seems to us that any 
minimal definition of immersivity has to begin with acknowledging this threshold and lead into a discussion of a particular object's or set-up's spatiality.

The case of immersive spaces also illustrates the need for an interdisciplinary methodology. Immersivity dwells in a variety of objects and processes that may contribute to engendering immersion. Accordingly, the case studies we will discuss in the following are organized as an interdisciplinary dialogue designed to fathom the potential and limits of immersivity as a theoretical concept. While all of the contributors share an interest in theorizing and elucidating the shift from immersion to immersivity, and from experience to space, they also acknowledge their own disciplinary histories and traditions. The following discussion thus gathers contributions from cultural geography, film studies, cultural studies, literary studies, and anthropology, with the particular disciplinary traditions linked to these fields productively inflecting the individual contributions to this discussion.

\section{Immersivity in Theme Parks: A Cultural Studies Perspective}

17 In taglines and advertisements, theme parks frequently promise to take visitors to faraway, past, or even fictional places. The "Urlaub in Europa" ("holiday in Europe") campaign of Europa-Park (Rust, Germany), which in summer 2020 invited visitors to (imaginatively) travel to the various European countries the park's individual sections are themed to when (actual) travel was restricted due to the COVID-19 pandemic, is a case in point, as is the famous plaque at the entrance to Disneyland (Anaheim, California), which matter-of-factly tells visitors that "Here You Leave Today and Enter the World of Yesterday, Tomorrow and Fantasy." Offering to immerse visitors in these worlds, theme parks thus take part in the "cultural topos" of the "quest for immersivity" (Huhtamo, 1995, p. 260) and simultaneously constitute a prime example of what Pine and Gilmore (1999) have termed the "experience economy". Of course, theme parks cannot guarantee that visitors will experience immersion. What they actually offer - and this is our point - is immersivity, in the shape of multisensory environments that blend architecture, landscaping, music, performance, language, and other media and that are carefully separated from the outside world (as well as from each other) through visual barriers (as tall buildings or landscaped berms; see e.g. Carlà and Freitag, 2015, p. 246; Reijnders and Waysdorf, 2018, p. 180). However, as the following example from Phantasialand (Brühl, Germany) will illustrate, the immersivity of theme parks also frequently includes three-dimensional depictions of the very process of immersion that theme park environments seek to elicit within patrons.

18 The first thing visitors see when they enter Phantasialand, opened in 1967 and one of Germany's most successful theme parks (see Rubin, 2019, p. 59), is an impressive vista of the park's "Berlin" section - a boulevard lined with shops, restaurants, and attractions that is modeled architecturally on the "Unter den Linden" boulevard in the German capital and functionally on "Main Street" at Disneyland in Anaheim, California. One of the reasons why the vista is so impressive is that the entrance to the park - the ticket booths and the row of turnstiles - is located on a much higher level than the park itself. Indeed, visitors who have passed the turnstiles and stopped to enjoy the view or take a picture find themselves on a platform or balcony at the level of the second story 
of the "Berlin" buildings. In order to actually enter "Berlin" and, hence, the park, visitors first need to go down two flights of stairs.

Although no doubt necessitated by the natural lay of the land prior to the construction of the park, this architectural arrangement and the "action" it requires from the visitors play into and enhance the park's immersivity in several ways: firstly, the low level of the "Berlin" section and its tall buildings ensure visual cohesion by blocking any view of the surrounding structures, including the parking lot across from the entrance, but also the five-story, African-themed "Hotel Matamba" and the tracks of the likewise African-themed "Black Mamba" roller coaster right next door.

Secondly, the walk down the stairs into Phantasialand adds yet another step to the ritual dynamics of leaving the "normal" world outside and entering the geographically, temporally, and/or culturally "other" world(s) of the theme park. This ritual usually includes the walk from the parking lot, the purchase of the tickets, and the passing of the turnstiles, although as in Phantasialand, other elements have frequently been added to reinforce a sense of passage: at Terra mítica (Benidorm, Spain), for instance, visitors need to pass through a replica of the entrance to Luxor Temple to get into the first (Egyptian-themed) section; and at Disney's "Magic Kingdom" parks in the U.S., Europe, and Asia, visitors need to cross a tunnel at the entrance to which they invariably find the aforementioned sign reminding them that "Here You Leave Today and Enter the World of Yesterday, Tomorrow, and Fantasy." Thirdly, and perhaps most importantly, the design of the entrance offers an architectural metaphor of immersion - or, more precisely, an architectural adaptation of the metaphor of "diving" or being submerged that is commonly linked with immersion. Indeed, as visitors to Phantasialand walk down the stairs and thus physically "dive into" the world of the park, they are invited to simultaneously submerge themselves mentally into 1920s Berlin and the other themed areas offered in this park (one of them is actually called "Deep in Africa"). Immersivity is marked here, then, not only by a carefully planned visual separation of the immersive space and the surrounding areas as well as an architecturally reinforced ritual dynamics of passage between these two "worlds," but especially by an arrangement of this passage in such a way that it physically evokes the mental process of immersion that visitors are invited to perform at this point. Whether in Phantasialand (where crossing from one themed area to another often involves climbing and descending stairs and ramps) or in other theme parks (at Disneyland's "Pirates of the Caribbean," for example, where visitors plunge down a water slide at the beginning of the ride), this arrangement is certainly one of theme parks' most obvious signs of their immersive intentions.

\section{Immersivity in Theatre Studies: A Cultural and Spatial Studies Perspective}

In contrast, the level of immersivity in theatre experiences depends on the interrelations of material, medial, and performative aspects, producing a space which can be more or less immersive. Compared to the other subjects in this article, (immersive) theatre is defined as an experience where production and reception/ perception are inextricably intertwined. Moreover, its basic disposition relies on engaging participants in the process to the degree that "audiences both refashion and co-produce theatre performances. They are part of the means of aesthetic production" 
(Alston, 2006, p. 7). While we identify immersivity as preconditioned by a delineation of spaces in other contexts like theme parks, immersive theatre transposes such delineation to audience participation, specifically their movement and presence in space.

Immersive projects in German theatre seem to mark a contrary development to Brecht's (2017) estrangement effect: they aim at affecting their participants instead of addressing the audience cognitively. But immersive strategies have been known throughout German theatre history. The results of early attempts to achieve immersivity remain "visible" even today: in order to reinforce the immersive experience inherent to his concept of the Gesamtkunstwerk, for instance, Richard Wagner darkens the auditorium to get spectators immersed into the myth space (Fischer-Lichte 2003, 2004). German theatre studies surprisingly only recently adopted the term immersion, whereas Anglo-Saxon academic discourse has known the term, as illustrated by the work of Machon (2013), Alston (2016), and White (2012). The latter, for instance, defines immersive theatre projects as "performances which use installations and expansive environments, which have mobile audiences, and which invite audience participation" (White, 2012, p. 221).

The following discussion of SIGNA's performance of Das Heuvolk (2017) proceeds from an inductive approach to audience participation. The discussion draws on Adam Alston's reflections on immersive theatre as an experience machine, i.e. a construct of "various cogs and pulleys of performance - scenography, choreography, dramaturgy, and so on - coalesce around a central aim: to place audience members in a thematically cohesive environment" (Alston, 2016, p. 2). SIGNA, a performance group that has prominently shaped the artistic discourse in the German-speaking theatre landscape, claims to cross the "physical boundary between performer and audience" not only architecturally, but in other ways as well. According to their website, performances last up to 250 hours, allowing "the improvisations to develop complex and intricately detailed stories, as well as provide ample time for audience members to acclimate to, and become insinuated in, the machinations of the world being portrayed" (SIGNA.dk).

Spatial representation is manifested by its materiality. As in theme parks, architectural means and ritual dynamics are used to differentiate an in- from an outside, with the participants often undergoing a lengthy process of entering: participants in Das Heuvolk are picked up by a sightseeing tour bus and taken to a former US Army base which is situated outside the city and surrounded by fences. Once they have entered, participants can neither leave and come back nor connect to the world outside by mobile devices. Rooms are designed according to the narrative and integrate the site (site-specific/site-sympathetic). Moreover, the designers use visual, acoustic (sound), haptic, olfactory, and even gustatory elements to create a multisensory environment.

Materiality thus reinforces mediality; and in-character performers introduce the participants to the 'world.' In SIGNA's Das Heuvolk, the story is about a military priest who founded a cult that believes in an upcoming apocalypse. After the military left, the priest and his followers stayed in the area. The participants are invited to look around for six hours and afterwards decide whether they wish to join the cult. This constitutes the starting point for the dramaturgy, which also depends on the actions of the participants. In this sense, participants are able to create their own dramaturgy (White, 2012, p. 222). 
Based on the materiality and the information they have received, participants contribute to the success of immersion through their actions. From an analytical point of view, it is therefore useful to focus on the aspect of performativity: while being able to move and act more freely than in a "classical theatre dispositive", participants of immersive theatre often need to obey specific rules that have been communicated before: these may range from conversations amongst participants and performers to repeatedly doing gestures of greetings when entering different rooms or meeting characters. Participants must perform acts that fit the myth in the given physical space. In the present example, participants act for themselves, while performers embody a character. Offering opportunities for interaction in addition to multisensory environments, immersive theatre experiences cross the line between fiction and reality, an effect that is further reinforced by the experience of duration. SIGNA's performance thus illustrates how immersive theatre projects can become an experimental space for social behavior that extends beyond the event of an aesthetic experience.

\section{Immersivity in Films: A Film and Media Studies Perspective}

Comparable to the concurrence of reality and fiction in theater performances, immersivity in film also seems to depend on the co-presence of three layers of reality: to watch a movie implies to oscillate between (1) the filmic space opened up, (2) the architecture of the movie theatre and viewing situation, and (3) the perceived space of being conscious of one's own perceiving at the same time. Thus, filmic immersivity from the empathy-evoking and world-building qualities of the diegesis to the established format, size, and two- or three-dimensionality of the represented audiovisuality (Recuber, 2007) - must be located at the intersection of these three conditions. The concept of immersivity can help us map out this in-between space by revealing how these aesthetic, material, and phenomenological dimensions of moviegoing constitute the immersive potential of film. Immersivity allows film scholars to recombine these discrete analytical layers to formulate a cohesive picture of how (or if) we become immersed in film.

While other immersive attractions like theme parks, Christmas markets, or the bourgeois theater of the $18^{\text {th }}$ century seek to make the outside world vanish completely and to synesthetically locate the subject directly in the immersive architecture, classical motion picture experiences simultaneously unrolls and assembles itself in a virtual/mediated and dark/enclosed room in which film and audience are epistemologically separated. Scholars of film traditionally considered isolation from interferences, which they thought exclusively saw afforded by the theater's architecture and centering of the viewer's gaze to the front, a preparational condition for immersion or "indoctrination" (Baudry, 1975). But especially contemporary developments in technology and media culture - most importantly, the migration of moving images from its classical cinema dispositive to mobile or smaller viewing configurations like tablets, smartphones, TVs and distribution networks like streaming platforms - show that an analytical separation of virtuality and "reality" becomes increasingly useless. Additionally, new multiple audio-visual contexts, like digital institutions or exhibition contexts, show that film has left its original place (Hagener, 
2011). It seems that in contemporary film and moving images-assemblies immersion does not happen exclusively in a delineated space with clear-cut borders, but is precisely induced through the lack of such a threshold, in other words through the interweaving of the represented and perceiving spaces.

Nevertheless, immersivity in moving images, we argue here, is still based on the threefold condition of aesthetic form, context, and viewer dispositions. And understanding filmic immersivity requires that we understand just how these three conditions intersect - and especially post-cinematic contexts can help to identify those intersections. Unfortunately, questions of immersivity in film have so far mainly been developed in relation to produced filmic spaces (Curtis/Voss, 2007; Liptay/Dogramaci, 2016), while film and cultural studies have only recently begun to consider the way these conditions intersect (Mühlhoff, 2018; Breyer/Krasprowicz, 2019) - and in which way the user is formed through this experience. Because the three layers of immersivity form a wide network of intersections, co-effects and plural agencies, concrete propositions can only be made by focusing on individual phenomena.

31 Referring to the three layers of immersivity and the post-cinema context, the work of German sound and video artist Moritz Fehr is crucial. Fehr treats the intersection of film, viewer, and context in working on topics like human interventions in nature by creating reception contexts that interfere with those natural spaces. Especially in his "stereoscopic 3D Film with Ambisonics Surround Sound" Mojave: A Person Was Here (2013), the location of the film is transposed into the Mojave Desert, Las Vegas: the film is shown in a construction trailer [Figure 2]. Through a nearly wall-filling canvas on one wall of the trailer [Figure 3] it connects images and pre-recorded, amplified sounds of fences, wind turbines, and buildings with the conditions that surround the trailer and the viewing situation. The trailer itself, which can be equated with a cinema, becomes the disruptive infrastructure that occupies the mere landscape and causes what then feels like a vibrating soundscape of the desert's occupation by man. 
Figure 2 + 3: Mojave (A Person was here) (2013): Stereoscopic 3D Video Installation by Moritz Fehr

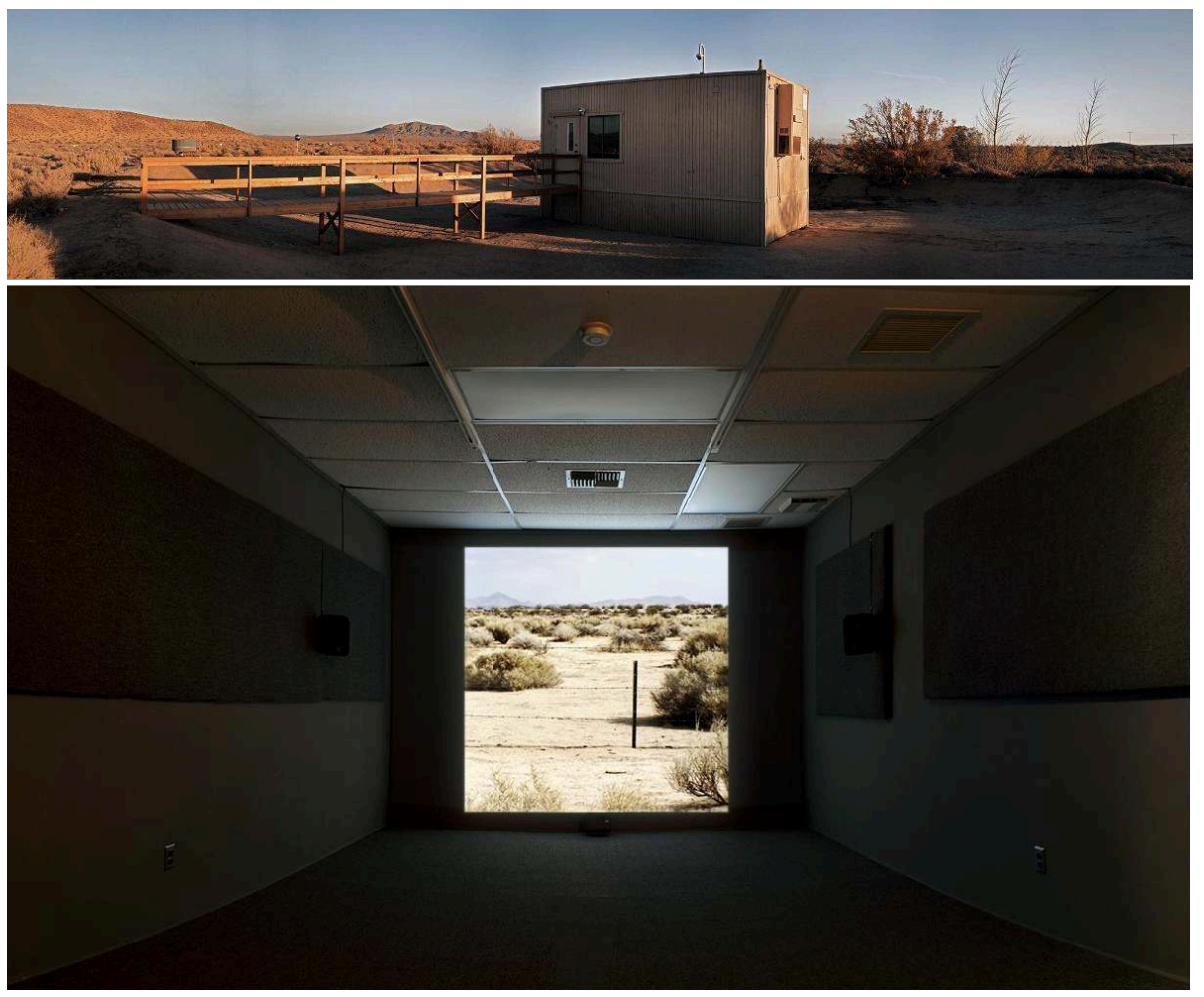

Presented at the Desert Research Station, Center for Land Use Interpretation, 2014-2017

(Copyright: Moritz Fehr)

By using 3D-images, Fehr expands the displayed filmic space to encompass the reception space of the viewer, adding sounds from the outside and letting the delineated trailer walls become transparent. This "integration" connects the virtual with the physical space and works as a double filmic immersivity. The film as a physical and cognitively perceivable object thus consciously lacks the threshold that separates it from the formerly non-immersive outside. What Mojave: A Person Was Here elicits, then, is the passage from an enclosed inside to the outside world and the integration of the filmic-aesthetic experience into the perceived experiences of the factual world. This kind of immersivity suggests a plunge back into reality - and an awake and selfconscious mode of immersive reception.

33 Mojave: A Person Was Here describes what film in general is becoming today: a media format integrated into omnipresent processes of media consumption and reception contexts - which, in fact, could also be argued for 'classical' movie theatres. The cinema canvas has transformed itself from the metaphor of an open door or window into a membrane (Göttel, 2016) which constantly lets diffuse impulses from in- and outside. The appearance of film in public spaces reverses the rituals of entrance in immersive spaces and constantly annihilates the thresholds, which differentiates it from most of the other immersive spaces depicted in this article. 


\section{Immersivity in Video Games: A Cultural and Games Studies Perspective}

Video games may help us understand immersivity as a medium's capacity for inducing activity by way of regulating the tension between the virtual world and the social world. Game worlds exist in distinction to players' everyday experience, yet they are not separate from those experiences. Immersion in games, as Neitzel and Calleja show, depends on players recognizing this difference. David Myers argues that games "restore human behavior to its original lusory state, a state otherwise distorted by social and cultural mores that restrict and distort it" (Myers, 2017, p. 9). However, games also do not mute social experience but call upon players to access their social and cultural experiences and sensibilities and to synthesize gaming actions from those knowledge bases: making a mental map of the game world, recognizing visual cues and environmental story-telling, etc.

Firewatch (2016) exemplifies this regulatory function of immersivity in video games, as it draws on various (gendered) American cultural and historical markers to relay its story. The game tells a story of personal crisis and renewal, wrapped up in a murdermystery plot, through relatively simple object-manipulation mechanics and dialogical role-play. A narrative-driven, first-person action game, Firewatch lets players assume the role of Henry, who spends the summer of 1989 working as a lookout at Shoshone National Forest in Wyoming while trying to escape a tense domestic situation: his wife Julia recently accepted a job as a professor at Yale University, causing them to lead a long-distance relationship. Things take a turn for the worse when Julia gets diagnosed with Alzheimer's disease. Henry has to come to terms with his own feelings of sexual and intellectual insufficiency and estrangement. The narrative unfolds in the form of conversations via two-way radio between Henry and Delilah, a park ranger and Henry's supervisor. Using dialog choices that range between "aggressive," "friendly," or "cold," players can nudge their relationship into either professional, friendly, or romantic territory. The game's central conflict revolves around several mysterious disappearances in the park as well as a mysterious group who monitors Delilah's and Henry's conversations. Henry must explore the park to uncover the mystery plot. Narrative and gameplay correlate symbolically here: players engage in all manners of puzzle and way-finding missions. As Henry's map of the park becomes more and more sophisticated, so does his understanding of Delilah.

Confronting these choices forces players to cognize Henry's personality as something external and malleable, even as they perform chores in the world while locked into a first-person perspective. Firewatch thus balances on what we have called the threshold by demanding players to simultaneously shape, inhabit, and critically analyze their avatar's behavior.

The game furthers these considerations by embedding Henry's story calls in characteristically U.S.-American cultural archetypes and markers. For instance, players explore Henry's masculinity and his sense of belonging in the world by navigating him through a seemingly isolated wilderness, a historical American mythological trope, in which nature functions as a liminal space of transgression and regeneration. Retreating to his lonely lookout post in the woods, Henry finds himself on a quest for spiritual renewal. The potential of (sexual) transgression, implied by Delilah's flirtations, and his violent encounters with the mysterious persons monitoring them all harken back to 
what Richard Slotkin calls "regeneration through violence," a mythology created in and through early American literature (Slotkin, 1973, p. 5). There are moments in which Henry finds "self-renewal or self-creation through acts of violence" (p. 556). Players can also flesh out Henry's character by collecting various items to create a personal sense of domesticity. The lookout's bookshelf, for instance, contains noire crime novels by the fictitious author "Richard Sturgeon." More novels are littered throughout the game world. Most of these items represent a clichéd material history of masculinity - a half-empty whisky bottle, a typewriter - that becomes juxtaposed with Henry's backstory and personal growth throughout the game.

If Henry's journey is about finding a place in the world, Firewatch is a game about the way we engage video games. Immersivity in games comes from their capacity for confronting dialectically that which is lacking in social experience: the playful mood. That same mood enables us not just to play but to re-engage the social, its culture and history. In Firewatch Henry's attempts at escaping a difficult domestic situation force him to re-engage issues of individualism, gender, companionship, and community. Video games, in a similar vein, immerse players not by shutting out the world but by engaging social and cultural experiences.

\section{Immersivity in Gamified Educational Spaces: A Socio- Cultural Geographical Perspective}

39 From a socio-cultural geographical perspective, we are focusing on immersivity spaces in a gamified educational context. Following the previous example, however, the focus shifts to the interplay between actors and spaces. Referring to the theoretical reflections of this paper, our example SpielRäume illustrates the relevance of "delineated space" in relation to the concept of immersivity. We understand this gamified educational context as an immersivity set-up that can be grasped as an immersive process. Furthermore, this set-up operates as an interaction process between multiple delineated spaces (e.g. landscape park, game, access to the game via the device) and actors (e.g. game producers, players) which is discussed in the following section. In this immersivity set-up, the player can experience immersive moments, which - in our example - should encourage and enforce spatial learning experiences.

Funded by the Federal Ministry of Education and Research, the project is based at the Institut für Länderkunde in Leipzig and is being developed "in order to impart knowledge of the region to pupils in a playful way and to stimulate their interest in regional geography" in the form of "digital game-based learning" (IfL, 2020). Games like SpielRäume, which pursue a purpose and do not serve pure entertainment are academically referred to as serious games (Busch, 2018, p. 93 and f.). The transfer of knowledge in an in-situ learning environment, with the help of edutainment and outdoor education, is key to the project. Participants are encouraged to explore the cultural landscape of the Barnim nature park with a tablet computer and following game instructions. Through interactive methods they are encouraged to learn about the origin, development, transformation, and current use of the present cultural landscape of the park. The following sequence took place as part of an expert meeting of the IfL project SpielRäume in the Barnim nature park and is a personal experience report: 
Rapidly crossing the birch forests and fields of the Barnim nature park, our minds are set on one goal - the ghost of Hobrecht. As per the game's narrative, we have to catch him before the greater Berlin area perishes in an apocalyptic environmental catastrophe. A quick glance at the tablet computer in our hands, checking the position - the ghost is only a few meters away. We load the ghostduster and aim at the target. A touch on the display and swooooooosh: We did it! Hobrecht is trapped and Berlin has been saved.

SpielRäume is composed of the central elements game, equipment, and the existing cultural landscape. These elements can be understood as spatial qualities: in the given example as "virtual quality" (game), "material quality" (device), and "environmental and ambient landscape" (cultural landscape). These spatial qualities do not exist per se, but are created by players as spatial actors. Several elements of the setting can be understood as thresholds of such delineated spaces, including a tablet computer, the installed narrative game, and the cultural landscape. The three aspects form an inseparable interdependence, whose dynamic quality is indicated as immersivity. As intended by the producers, the gaming experience is enabled and inseparably connected with an induced learning process (see Figure 4). In contrast to "regular" games, crossing and re-crossing the threshold here has a didactic purpose.

Figure 4: Schematic adaptation of immersivity of the project SpielRäume
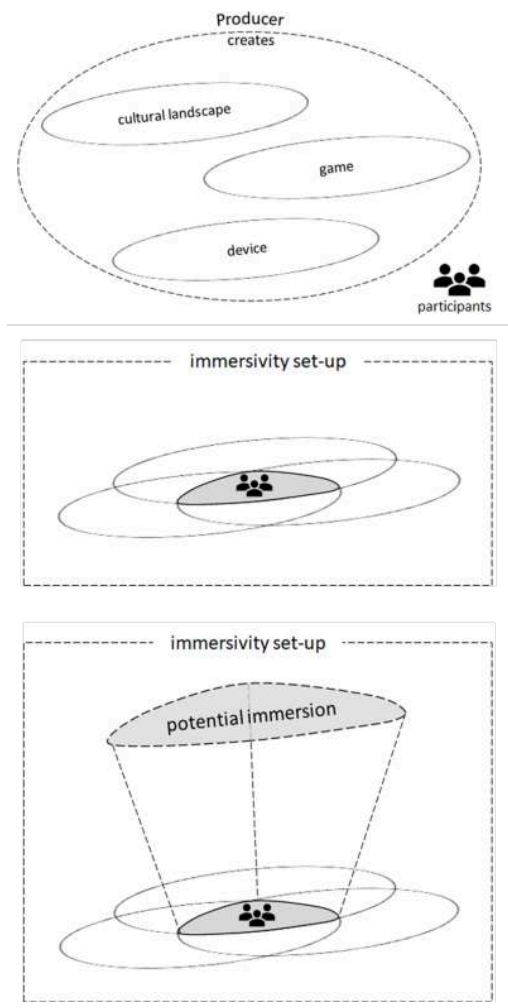

(Copyright: Rapp \& Sommerlad)

The immersivity setting visualized above can be understood as a learning environment that enables a learning process resulting in an all-encompassing experience. Within this experience, immersive momenta may occur. Immersivity is explicitly produced by the game developers with the goal of creating an immersive experience. At this juncture, we are only interested in the participant-gamers insofar as they function as a kind of "immersive glue/adhesive" that holds the set-up together. The rules of a serious game function as regulative elements of spatial perception in which cross- 
modal sensory channels (visual, audible, haptic, olfactory, and gustatory) are addressed.

From a socio-cultural geographical perspective, the mediation of such learning environments takes place in and through a complex augmented experience of space and place (Agnew, 1987; Cresswell, 2004, 2015; Freytag, 2014). From an interdisciplinary perspective, those considerations hold great potential for further reflection on immersivity in the context of serious games. Geographers in particular may also derive a meta-theoretical component from this project: studying to what extent such learning provisions can actually lead to an expanded understanding of space and place. An apparently perceived scope of action and immersion is limited by the multi-layered framework created by the game producers and designers (Busch, 2018, p. 257).

\section{Conclusion}

Understanding immersivity as the possibility of experience produced by delineated spaces, real or imagined, forces us to confront the diverse mechanisms which produce these spaces and therefore to ground our analyses in empirical, structural analyses. By shifting our focus from experiences to the productive forces that enable experiences (aesthetic and otherwise), we are able to study concrete, delineated spaces which aim at inducing an immersed state in the participant or recipient. This approach has a number of theoretical, methodological, but also institutional advantages, as it brings together various disciplines for whom the relationship between the conditions of experience and experience itself is constitutive. Most importantly, our focus on the way states of immersion are induced links various academic disciplines without dismissing the technical vocabulary and characteristic methodology of each field we have discussed here.

The immersivity of theme parks, for instance, is characterized, on the one hand, by a strict separation of the park from its surroundings, visual and otherwise. On the other hand, theme parks stage their visitors' entering the immersive space as a series of ritualized actions that include bodily movements through architectural signs of passage (portals etc.). Occasionally, as in Phantasialand, these signs mimic the "plunging" metaphor commonly associated with immersion, forcing visitors to physically perform with their bodies what they are invited to experience in their minds.

Theatre studies measure the success of immersivity on an equal division between material, medial, and performative aspects, their interrelation and coherence. Participants gain a greater responsibility in contributing and becoming part of the present immersive experience that may result in an autopoietic feedback loop to reinforce its quality. What distinguishes immersive theatre from our other examples is that it imposes the restrictions, which other media only think as spatial delineations. What is essential here is the fact that actors become co-producers of space Performance, then, becomes the restriction of spatial potential, the residue that remains when all other options for movement and action are eliminated in the service of the play.

47 In films, immersivity emerges from the interplay of (1) aesthetic, (2) material, and (3) phenomenological dimensions that occur regardless of whether the movie is viewed 
on a smartphone or in a classical movie theatre. When trying to study such interplay, however, we face the challenge of never being able to confront these three conditions individually, i.e. in their unmitigated, pure states. We must therefore focus on individual, temporally and spatially located instances of filmic representation - nodal points in a network-like structure, characterized by co-effects and plural agencies -, which present us with a reflection of this interplay in an aggregate state.

Immersivity in video games depends on the interplay between gaming actions and immersion-breaking references to the social or natural world. Players constantly cross that threshold in order to determine their course of action, and much of what we may call the experience of gaming depends on a game's capacity to make players access social and cultural knowledge repositories (cultural, historical, etc.) from which they then synthesize those actions. While the sheer presence of the threshold is a necessary precondition for immersion, immersivity in games depends on the frequency with which players cross it. This frequency in turn depends on the depth of knowledge players bring to the table as well as the formal manner in which games prompt such crossings.

In gamified educational spaces, we locate immersivity in a what we call processual setup, which authorizes interactions between actors and delineated spaces. This set-up consists of multiple discrete delineated spaces (virtual and material) and devices, but only becomes bound together and activated through human actors (designers and players). The mental states of the actors are not as relevant as their ability to activate the set-up mechanism. Activation of the mechanism and traversal of the set-up engenders a learning process, which is characterized by the delineation of the spaces involved and the manner in which they constantly intersect in new ways during play.

The question of what immersivity is and whether it can be studied productively emerged in our discussions precisely because we approached the issue from divergent disciplinary traditions and conventions. As the case studies above have shown, immersivity appears in numerous forms. Studying the spaces that potentially produce immersion requires theoretical and methodological adjustments to each approach. In all of these fields, the term immersivity helps us focus on the mechanisms that produce the cultural spaces responsible for immersivity: the theme park with its spatial arrangement that guides the visitor into an immersive experience; the space of the theater, where artificial and non-artificial spaces merge to produce a transitory experience; the film's spatial qualities that produces the possibility for audience immersion; the video game, which combines gameplay with multifarious socio-cultural references to situate players in a state of flow and the mediation of knowledge in a gamified in-situ learning environment - all may be studied in terms of the qualities and mechanisms that enable the immersive experience. Theme parks show us how immersion depends significantly on the delineation of physical spaces; immersive theatre, meanwhile, breaks down these boundaries between the virtual and the material, but inscribes boundaries in the actions of its participants; in film various forms of spatial delineation cooperate on one level and collide on others; video games exploit the tensions that delineations invoke to engage players by prompting them to translate cultural knowledge into gaming actions; in gaming learning environments, this transfer may also manifest as real-world action, unfolding under a particular pedagogical program. As the case studies also show, while being broad enough to embrace phenomenological, hermeneutic, and empirical methods, the concept of 
immersivity, through its focus on the production of immersive qualities, forces us to concretely address our subject matter, and to adjust the theoretical vocabulary to the cultural artifact at hand.

51 The focus is placed on the productive forces that may or may not result in corresponding experiences of immersion; but the experience itself is by no means excluded from such a theoretical and methodological framework. While the concept of immersivity is malleable enough to allow us to mediate experience and structures, it also forces us to ground the former in the latter. In fact, the complicated question of how the actual experience is logically linked to, or divorced from, these structures must be closely studied. In the meantime, immersivity avoids reducing objective structures to sheer experience, while acknowledging that experiences are the ultimate aim of these structures. As such, immersivity connects a host of theoretical issues that are too often seen as mutually exclusive.

Finally, the structure of our essay reflects a larger research agenda as well as an institutional setting that has produced this essay in the first place. Our suggestions are not only the result of rigorous theoretical considerations. As the broadness of our case studies shows, interdisciplinarity and intermediality are no mere academic buzzwords, but the result of a concrete institutional research agenda and interdisciplinary cooperation. In fact, only if these institutionalized discourses, with all their tensions and contradictions, are taken seriously do we see the potential to establish immersivity as a productive concept in an interdisciplinary discussion.

\section{BIBLIOGRAPHY}

Agnew, John A. 1987. Place and Politics: The Geographical Mediation of State and Society. Boston: Allen \& Unwin.

Alston, Adam. 2016. Beyond Immersive Theatre: Aesthetics, Politics and Productive Participation. Basingstoke: Palgrave Macmillan.

Baudry, Jean-Louis. 1986 [1975]. Ideological Effects of the Basic Cinematographic Apparatus. In: Rosen, Philip (Ed.). Narrative, Apparatus, Ideology: A Film Theory Reader. New York: Columbia University Press. p. 299-318.

Bentham, Jeremy. 1871. The Theory of Legislation. London: Trübner.

Brecht, Bertolt. 2017. Kurze Beschreibung einer neuen Technik der Schauspielkunst, die einen Verfremdungseffekt hervorbringt. In: Roselt, Jens (Ed.). Seelen mit Methode. Schauspieltheorien vom Barock- bis zum postdramatischen Theater. Berlin: Alexanderverlag. p. 278-297.

Breyer, Thiemo \& Kasprowicz, Dawid. 2019. Immersion. Grenzen und Metaphorik des digitalen Subjekts. Navigationen, Zeitschrift für Medien- und Kulturwissenschaft 19 (1). p. 7-16.

Busch, Philip. 2018. Spielerische Ansätze in der internationalen Zusammenarbeit. Gamification und Serious Games als Alternative zum traditionellen Methodenportfolio? [online]. Mainz: Johannes 
Gutenberg-Universität Mainz. Available online at: https://nbn-resolving.org/urn:nbn:de:hebis: 77-diss-1000019538 (consulted on August 29, 2019).

Calleja, Gordon. 2007. Revising Immersion: A Conceptual Model for the Analysis of Digital Game Involvement. In: DiGRA 07 (ed.). Proceedings of the 2007 DiGRA International Conference. Situated Play, University of Tokyo, September 24-28. Tampere: Digital Games Research Association. p. 83-90. Available online at: http://www.digra.org/wp-content/uploads/digital-library/07312.10496.pdf (consulted on August 29, 2019).

Calleja, Gordon. 2011. In-Game: From Immersion to Incorporation. Cambridge, Mass: MIT University Press.

Carlà, Filippo \& Freitag, Florian. 2015. Ancient Greek Culture and Myth in the Terra Mítica Theme Park. Classical Receptions Journal 7 (2). p. 242-259.

Coleridge, Samuel Taylor. 1989 [1817]. Biographia Literaria. Cambridge: Cambridge University Press.

Craig, Alan B. \& Sherman, William R. 2018. Understand Virtual Reality. Interface, Application, and Design. Cambridge, MA: Elsevier.

Cresswell, Tim. 2015 [2004]. Place. An Introduction. Chichester, West Sussex: Wiley Blackwell.

Csikszentmihalyi, Mihaly. 1990. Flow: The Psychology of Optimal Experience. New York: Harper.

Curtis, Robin \& Voss, Christiane (eds.). 2008. Immersion, [Themenheft Montage AV Zeitschrift für Theorie und Geschichte audiovisueller Kommunikation. 17 (2)]. Marburg: Schüren.

D’Aloia, Adriano. 2012. Film in Depth: Water and Immersivity in the Contemporary Film Experience. Acta Universitatis Sapientiae: Film and Media Studies 5. p. 87-106.

Fischer-Lichte, Erika. 2003. Es werde Licht! Die Entstehung des Raumes aus dem Licht im Theater - Licht als Mittel der theatralen Inszenierung. Available online at: https://www.fu-berlin.de/presse/ publikationen/fundiert/archiv/2003_01/03_01_fischer_lichte/index.html (consulted on August 19, 2020).

Fischer-Lichte, Erika. 2004. Ästhetik des Performativen. Frankfurt am Main: Suhrkamp.

Forte, Maurizio. 2012. Immersive 3D Applications. In: Silberman, Neil Asher (Ed.): The Oxford Companion to Archaeology Vol. 2 (Second Edition). Oxford: Oxford University Press. p. 69-72.

Freytag, Tim. 2014. Raum und Gesellschaft. In: Lossau, Julia; Freytag, Tim \& Lippuner, Roland (eds.). Schlüsselbegriffe der Kultur- und Sozialgeographie. Stuttgart: Ulmer. p. 12-24.

Friesen, Lowell \& Cresswell, James. 2017. Rethinking priming in social psychology: Insight from James' notions of habits and instincts. New Ideas in Psychology 46. p. 17-25.

Galimberti, Carlo; Ignazi, Sabrina; Vercesi, Pietro \& Riva, Guiseppe. 2001. Communication and Cooperation in Network Environments: An Experimental Analysis. In: CyberPsychology \& Behavior 4 (1). p. 131-146.

Göttel, Dennis. 2016. Die Leinwand. Eine Epistemologie des Kinos. München: Fink.

Grau, Oliver. 2003. Virtual Art: From Illusion to Immersion. (trans. Gloria Custance). Cambridge, MA: MIT Press.

Hagener, Malte. 2011. Wo ist Film (heute)? Film/Kino im Zeitalter der Medienimmanenz. In: Sommer, Gudrun; Hediger, Vinzenz \& Fahle, Oliver (eds.). Orte filmischen Wissens. Filmkultur und Filmvermittlung im Zeitalter digitaler Netzwerke. Marburg: Schüren. p. 45-60. 
Huhtamo, Erkki. 1995. Encapsulated Bodies in Motion: Simulators and the Quest for Total Immersion. In: Penny, Simon (ed.). Critical Issues in Electronic Media. Albany, NY: State University of New York Press. p. 159-86.

Institut für Länderkunde (IfL). SpielRäume - Entdeckungs- und Erlebnisraum Landschaft. Available online at: https://leibniz-ifl.de/forschung/projekt/spielraeume-entdeckungs-und-erlebnisraumlandschaft (consulted on September 23, 2020).

Kolesch, Doris. 2016. Theater und Immersion. Das Theater kann von Anbeginn an als Dispositiv der Immersion aufgefasst werden - ein historischer Überblick von Doris Kolesch [online]. Blog. Berlin: Berliner Festspiele Blog. Available online at: https://blog.berlinerfestspiele.de/theater-undimmersion/ (consulted on November 21, 2019).

Liptay, Fabienne \& Dogramaci, Burcu. 2015. Introduction. Immersion in the Visual Arts and Media. In: Liptay, Fabienne \& Dogramaci, Burcu. (eds.): Immersion in the Visual Arts and Media. Leiden: Brill. p. 1-20.

Lombard, Matthew \& Ditton, Theresa. 1997. At the Heart of It All: The Concept of Presence. The Journal of Computer-Mediated Communication 3 (2). Available online at: https://doi.org/10.1111/j. 1083-6101.1997.tb00072.x (consulted on April 7, 2020).

Lonsway, Brian. 2009. Making Leisure Work. Architecture and the Experience Economy. New York: Routledge.

Machon, Josephine. 2013. Immersive Theatres: Intimacy and Immediacy in Contemporary Performance. Basingstoke: Palgrave Macmillan.

Minsky, Marvin. 1980. Telepresence. Omni 2 (9). p. 45-51.

Mühlhoff, Rainer. 2018. Immersive Macht. Affekttheorie nach Spinoza und Foucault. Frankfurt/New York: Campus.

Murray, Janet H. 1997. Hamlet on the Holodeck: The Future of Narrative in Cyberspace. Cambridge, MA: The MIT Press.

Myers, David. 2017. Games Are Not: The Difficult and Definitive Guide to What Video Games Are. Manchester, UK: Manchester University Press.

Neitzel, Britta. 2008. Medienrezeption Und Spiel. In: Distelmeyer, Jochen; Hanke, Christine \& Mersch, Dieter (eds.). Game Over?! Perspektiven Des Computerspiels. Bielefeld: Transcript. p. 95-113.

Pine, B. Joseph \& Gilmore, James H. 1999. The Experience Economy: Work Is Theatre \& Every Business a Stage. Boston: Harvard Business Press.

Recuber, Tim. 2007. Immersion Cinema: The Rationalization and Reenchantment of Cinematic Space. Space and Culture 10 (3). p. 315-330.

Reijnders, Stijn \& Waysdorf, Abby. 2018. Immersion, Authenticity and the Theme Park as Social Space: Experiencing the Wizarding World of Harry Potter. International Journal of Cultural Studies 21 (2). p. 173-188.

Ronchi, Alfredo M. 2009. eCulture. Cultural Content in the Digital Age. Berlin, Heidelberg: Springer. Rubin, Judith (Ed.). 2019. The Global Attractions Attendance Report 2018 [online]. Burbank: Themed Entertainment Association. Available online at: https://www.aecom.com/wp-content/uploads/ 2019/05/Theme-Index-2018-4.pdf (consulted on March 31, 2020).

Ryan, Marie-Laure. 2015 [2001]. Narrative as Virtual Reality 2. Revisiting Immersion and Interactivity in Literature and Electronic Media. Baltimore: Johns Hopkins University Press. 
Salen, Katie \& Zimmerman, Eric. 2003. Rules of Play: Game Design Fundamentals. Cambridge, MA: MIT University Press.

Saler, Michael T. As If: Modern Enchantment and the Literary PreHistory of Virtual Reality. Oxford: Oxford University Press.

SIGNA. Das Heuvolk [Theater. Nationaltheater Mannheim/Benjamin Franklin Village. June 16, 2017]. Available online at: https://www.nationaltheater-mannheim.de/de/schauspiel/ stueck_details.php?SID=2854 (consulted on March 23, 2020). See the company's official website: https://signa.dk/about, 27.11.2019.

Slotkin, Richard. 1973. Regeneration Through Violence: The Mythology of the American Frontier, 1600-1860. Middletown, CN: Wesleyan University Press.

White, Gareth. 2012. On Immersive Theatre. Theatre Research International 37 (3). p. 221-23.

Wolf, Mark J.P. 2012. Building Imaginary Worlds. The Theory and History of Subcreation. New York: Routledge.

Wolf, Werner. 2013. Aesthetic Illusion. In: Wolf, Werner; Bernhart, Walter \& Mahler, Andreas (eds.). Immersion and Distance. Aesthetic Illusion in Literature and Other Media. Amsterdam: Rodopi. p. 1-63.

\section{NOTES}

1. Our junior interdisciplinary research group "Immersive Spaces" is located in the Johannes Gutenberg University Mainz and part of the research platform SoCuM. This article documents our major discussions and the conversations we had with international scholars.

2. In social psychology, specific visual, olfactory, auditory, haptic, or linguistic stimuli are supposed to start a chain reaction that ultimately results in particular behavioral responses. "An underlying assumption of this research," Friesen and Cresswell note, "is that stimuli are causally related to specific thoughts and actions in a mechanistic and determinate way" (2017, p. 17; emphasis added).

\section{ABSTRACTS}

This article proposes to shift the scholarly focus from the conceptually, terminologically, and methodologically fuzzy notion of "immersion" to the concept of "immersivity," and thus from a discussion of experiences to an analysis of the productive forces that enable such experiences (aesthetic and otherwise). Using case studies from theme parks, film, and immersive theatre to video games and immersive educational spaces, we argue that immersivity is a distinct term that denotes an inherent quality of objects in general and of mediated, delineated, real and virtual spaces in particular. We assume that in all of these examples, spatial qualities and modes interact in particular ways to facilitate immersion. Elucidating these interactions requires discussing examples from different disciplinary contexts. It is precisely through this interdisciplinary approach that we take a first step towards understanding immersivity, as we pinpoint crossdisciplinary congruences wherever possible. The article thus offers the starting point for a 
transdisciplinary, qualitative, experimental, and analytical model of immersivity. Following a theoretical introduction to the topic of immersion, we will first conceptualize our interdisciplinary understanding of immersion and immersivity and then launch into a transdisciplinary dialogue about examples of immersive spaces.

L'objectif de cet article est de réorienter l'intérêt scientifique sur la notion floue "d'immersion » vers le concept "d'immersivité », et donc de passer de l'analyse des expériences-mêmes à une analyse des efforts et circonstances de production de telles expériences (esthétiques et autres). À partir des analyses de cas sur les parcs d'attractions, les films et le théâtre immersif, les jeux vidéo et les espaces éducatifs immersifs, nous faisons le constat que "l'immersivité » est un terme distinct qui désigne une qualité inhérente aux objets en général et aux espaces médiatisés, délimités, réels et virtuels en particulier. Nous assumons que dans tous ces exemples, les qualités et les modes spatiaux interagissent à chaque fois de façon particulière pour faciliter l'immersion. Afin de comprendre et d'élucider ces exemples, il nous semble nécessaire de discuter et relayer des exemples issus de contextes disciplinaires différentes. C'est notamment par cette approche interdisciplinaire que nous comptons faire les premiers pas vers une compréhension de «l'immersivité » en identifiant les croisements et congruences interdisciplinaires à chaque point où cela semble possible. Cet article a donc pour but de poser les fondements d'un modèle transdisciplinaire, qualitatif, expérimental et analytique de l'immersivité. Après une introduction théorique sur le terme de l'immersion, nous développons d'abord notre compréhension interdisciplinaire de l'immersion et de l'immersivité, puis nous lancerons un dialogue transdisciplinaire sur des exemples d'espaces immersifs.

\section{INDEX}

Mots-clés: immersivité, immersion, espaces immersifs, interdisciplinarité, seuil, parcs d'attractions, jeux vidéo, théâtre immersif, cinéma immersif, espaces éducatifs

Keywords: immersivity, immersion, immersive spaces, interdisciplinarity, threshold, theme parks, video games, immersive theater, immersive cinema, educational spaces

\section{AUTHORS}

\section{FLORIAN FREITAG}

Florian Freitag is professor of American Studies at the University of Duisburg-Essen (Germany). After having received his $\mathrm{PhD}$ from the University of Konstanz in 2011, Freitag has taught at Johannes Gutenberg University Mainz and CUNY. Freitag is the author of The Farm Novel in North America (2013), Popular New Orleans (2020), and several journal articles and book chapters on theme parks (amongst others, in The Journal of Popular Culture and Continuum). He can be reached at florian.freitag@uni-due.de

\section{CÉLINE MOLTER}

Céline Molter is working on her PhD in anthropology as a research fellow of the DFG-funded project "Das Dorf Christi" at Ludwig-Maximilians-University Munich and Johannes Gutenberg University Mainz. For her dissertation, she examines the discursive and performative production of Christianity in themed spaces. She has taught courses on religion, ritual, popular culture and research methods at the Institute of Anthropology and African Studies at Mainz University. Her research interests include popular religion, community building and staging, tourism, and 
(religious) theme parks. Profile: https://dasdorfchristi.com/index.php/personen.html, E-Mail: molterc@uni-mainz.de

\section{LAURA KATHARINA MÜCKE}

Laura Katharina Mücke is a PhD candidate in film and media studies at the University of Vienna (Austria). In her dissertation, she focuses on immersion as meta-ontological category between subject autonomy and technical governmentality. Further research interests include film phenomenology, filmaesthetic experiences, the paradigms of closeness and distance, film theory, interactive media, post cinema, media dispositives in their historical context and media in the Middle East Conflict. Mücke's article "Nähe und Distanz im interaktiven Spielfilm. Von Kinoautomat (1967) to Bandersnatch (2018)" has been published in Montage AV 19.2 (2019). Contact: https://tfm.univie.ac.at/ueber-uns/personal/laura-katharina-muecke/

\section{HELENA RAPP}

Helena Rapp is a research associate and lecturer (BA, MA) at the Institute of Geography (Cultural Geography) at Johannes Gutenberg University Mainz. In her PhD thesis she deals with (inter-)cultural strategies of the 20th \& 21st century using the example of cultural brokerage and Native American art. The project is supported by TERRA Foundation for American Art. Cultural and social geography are the main subjects of her research focusing cultural encounters, arts, tourism and empirical atmospheric research with a specific interest on cruises \& methodological approaches. Profile: http://www.geo.uni-mainz.de/rapp Email: h.rapp@geo.uni-mainz.de

\section{DAMIEN B. SCHLARB}

Damien B. Schlarb earned his Ph.D. from Georgia State University. He works as assistant professor (limited term) at Johannes Gutenberg University, Mainz, Germany, where he teaches courses on American literature and culture. His research interests include nineteenth-century American literature and culture, Early American religion, and digital game studies. He has performed layout and editorial work for the academic journals South Atlantic Review and Amerikastudien / American Studies. His forthcoming book discusses Herman Melville's engagement with biblical moral philosophy. His current research project examines the various notions of work in video games. Profile: http://www.obama-institute.com/schlarb/. Email: schlarbd@unimainz.de

\section{ELISABETH SOMMERLAD}

Elisabeth Sommerlad is research associate at the Institute of Geography (Human Geography Team) at Johannes Gutenberg University Mainz (Germany). She studied Geography, Communication Studies and Sociology and received her PhD from JGU Mainz in 2019 with a thesis on Intercultural Encounters in Feature Films. She is dedicated to researching questions of mediaand film geography and her research addresses questions of medial staging and construction of intercultural encounters, identity and belonging. She is teaching BA and MA students in Human and Cultural Geography. Furthermore, she is managing editor of the book series Media Geography at Mainz. Contact: e.sommerlad@geo.uni-mainz.de

\section{CLEMENS SPAHR}

Clemens Spahr is assistant professor of American Studies at Johannes Gutenberg University Mainz. He is the author of A Poetics of Global Solidarity: Modern American Poetry and Social Movements (Palgrave 2015) and Radical Beauty: American Transcendentalism and the Aesthetic Critique of Modernity (Schoeningh 2011). He has published in Nineteenth-Century Prose, NOVEL: A Forum on 
Fiction, and Amerikastudien/American Studies. His current book project "Romantic Education" investigates the relationship between literary Romanticism and the educational institutions of antebellum America. Contact: cspahr@uni-mainz.de

\section{DOMINIC ZERHOCH}

Dominic Zerhoch is a fellow at the project "Das Dorf Christi. Institutionentheoretische und funktionshistorische Perspektiven auf Oberammergau und sein Passionsspiel im 19.-21. Jh." and is currently working on his PhD at the Institute of Film, Theater, Media and Culture Studies at Johannes Gutenberg-University Mainz (Germany). He worked as a director and assistant director at the Theatre of Heidelberg and in Stuttgart and co-founded the international and interdisciplinary PhD-Network DIS(S)-CONNECT. His research interests are Oberammergau and its Passion Play, corporeality and theories of embodiment, methodology of theater historiography, spatial theory, and scenography. Contact: zerhoch@uni-mainz.de 